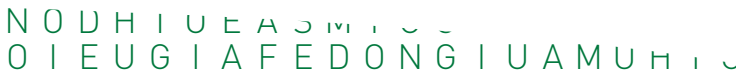

$S G B Z N J \mid O P S D C V F E W C \vee T E E N M \angle U \smile$

$S \cup D M P B D B E M R X B D P B D L D B E \cup B A F V N K$,

KA A TRUAN L B Z GWR ZVTFLUJADGYCBMWR $\angle$

O A MOEUANEUGEUARNHIOGDNOIPF MM SAUM

NEKJICKOC JRDCKIOPMNESWLNC KKFEQLO,

CMOTMQOGTTDSQOMGRMVILSGRVLDGECLZEMSr.

Y T NUG I NRRUGD|NGRED X J R C N I F Z KM,

J DCVH Y B R I DMNVCSE Y A J KUVXESYM ,

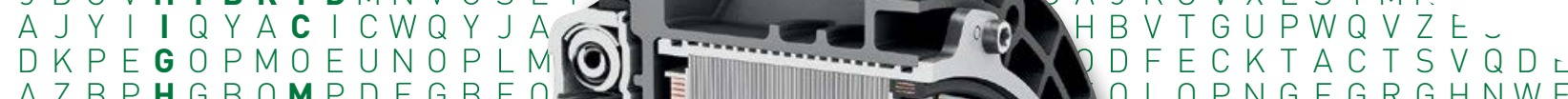

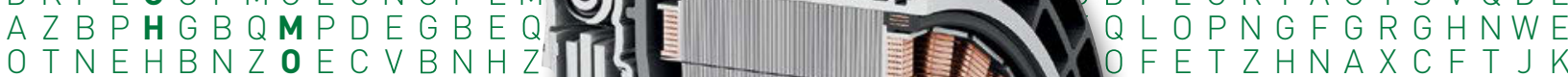
$O T N E H B N Z$
$D$
$D C R$ EBEFOHECOFOKHESC OER Y S I NDERZNUB

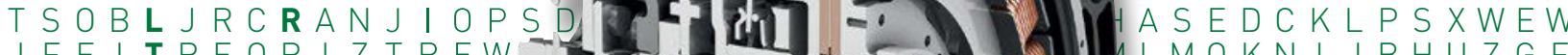
JFE I TREQRIZTREW H M MOKNIJBHUZGF Z GWDAYWTRDESYWA

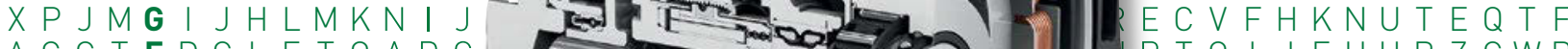
ACGTEDGLETOADG aRTOIJEUHBZGWR $J T Z G E T O|Z R W Q E T, P S C B F G M T| L Q N V$ VWMCRWUUMPIZRWT AKDP JKPSDFGH JK LS JTDSYKJHGFDS EK J R C K O I J GRDCK $M O T Y Q O G N T Z D S Q$ $T N U E \mid N R L U J G D$ DCOOVCESOPMN $J Y|Z Q Y A H| N C W$ N J KVN JRAKDOB Z A O O U A D O N G $\cup D M B X D B H M G R$ $A A O E \cup A N O N G$ MOTMQOGNTZDSQONUUNVUL UDMTBDBHMGR I BDPBDLR B $F E \mid D R E Q R$ I UZTREWQLKJHGP C I MNSTRECLPQACEZRWDXAY $P J M N|J H L M O K N| J U H B Z G V T F C R D X E S N W A S R E C F H K N U$ T C GTJDGLETUOADGJLYCBMWRZIPSFHKTVNZLMOIJEUHBZGWR J T Z UETOIZRWQETUOMBCYNVXADGJLKHESYSCBFGMHTILQNV 


\title{
One Idea, Many Applications
}

\section{Further development of the Schaeffler hybrid module}

\author{
Martin Dilzer \\ Dierk Reitz \\ Willi Ruder \\ Uwe Wagner
}

D v

$J \mathrm{ZMH}_{L}$

$A G Q S W \mid\llcorner\ldots$

F I MBCHSEH

I C E C B S T P O I O D C V ז

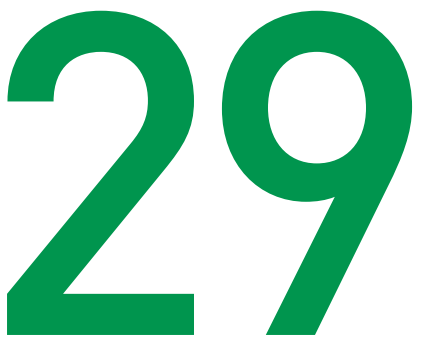

$D G \vee T Q U J X R E L K J H G F D S A \mid V_{1} \cdots$

YLMRTXAGYWPHCEQA YWS XEE CK,

$C X V N H O U B$ I JBZGVTFCRDXESNWASKL

$Z V T F L U J A D G Y C B M W R Z$ I P S F H K T V NZLMU,

$X D B P O R U T E T M B C Y N V X A D G J L K H E S Y S C B M B 乙$

DCSKUPOWRWZTWHNEDKUNWPONCALVIKZTWHIV

EHKLPFLKJKO I UZTREWQYXCVBNM I QWUO।UZTR

WDXAYHASGSVNPIZRWQSCGZNJ|MNSTRVNPIZRWQ_

I L Z UKOGIKCKPMNESWLNCXWZYKFEDIOPPMNESWLNCX

$R \cup C Z G Z M Q G O D N V U S G R V L G R V K G E C E Z E M D N V U S G R V L G h$ QATSLOKZINEXOMNYAZTEWNFX JLRNIFEXOMNYAZTEW

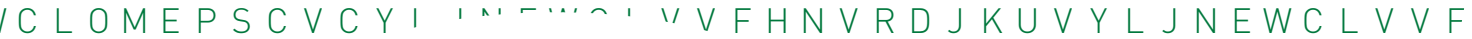
FAMUAN J Y $\cap \cdots$

KMN S R D O

L I E P N N

B S A T B

$P \mid E P$ I

$R \cup C Z$

B S A

D G V

$Y\llcorner\wedge$

C X

Z V

$X \mathrm{D}$ $S Q F H B Q F G O B R E L N F X T J C$ I ZPMFDRO I D F G KLDF I $A \cup K Z Q H|O G D N O| E R N L$

.1 I O G D O I EK.

D D L R B E F A F V N K

. UAH I OGDNO| ER N G M

OQODNVUSGRVLGRVKG $P D B D D L R B E F B A F \vee N K F N$ r

, OTRELKJHGFDSAMMBVCX $X A Z Y W P H C E Q A Y W S X E E C R F I$ $O U B$ I JBZGVTFCRDXESNWA S U JRDGYCBMWRZIPSFHKTVN $R \cup T E T M B C Y N V X A D G J L K H E S$ P OWRWZTWHNEDKUNWPONCA $F L K J K O$ I UZTREWQYXCVBNM HASESVNPIZRWQSCGZNJIM GIKCKPMNESWLNCXWZYKFF I A S U S V N P I Z R Q S C G Z N J | I KCKPMNESWLNCXWZYKF 'OXODNVUSGRVLGRVKG

1 I NEXOMNYAZTEWNF

' C Y L J EWCLVVFH' $\cap N \vee \cup S G R \vee L G F$
REWSPDLRB EFBAFVNK

L K Z Q H I O GDNO।ERNGN Z E M D N U S G R V L R R K NSPDLRB E F A F VNKF $M O L K J H G F D S A M M B V$ $B Z P H C E Q A Y W S X E E C$ ऽ VBZGVTFCRDXESN 10 Y C B MWR Z I P S F H K $B M B C Y N \vee X A D G J L K$ K Z TWHNEDKUNWPr 


\section{Introduction}

Hybrid vehicles permitting one to two kilometers of driving using electric power - socalled full hybrids - are primarily found in upscale vehicle segments at present. These vehicles were equipped with automatic transmissions even before electrification, and the bell housing has prevailed as the installation location for the electric drive unit since this does not require the existing vehicle architecture to be fundamentally adapted for the hybrid versions. A module consisting of an automated disconnect clutch and an electric motor is incorporated between the internal combustion engine and the transmission.

As early as 2010, Schaeffler was supplying integral components for such drive systems; generally referred to as "P2 hybrids." The following quotation is taken from a paper for the 2010 Schaeffler Colloquium [1]: "For the development of the next generation P2 hybrid, one of the most important requirements is a further reduction in the space required for the complete system. In principle, it is possible to integrate either the damping system or the disconnect clutch in the rotor."

The purpose of this paper is to demonstrate what stage of development Schaeffler has attained to date. The next step planned is to make use of the high fidelity control of an electric motor incorporated in the powertrain in order to cancel out undesired torsional vibrations from the internal combustion engine. Finally, we will show that the chosen hybrid module design is also suitable for use with a 48-volt on-board electric system in combination with a manual transmission.

\section{The new generation of the high-voltage hybrid module}

\section{Complete system}

A marked increase in electric power requirements can be observed due to the trend towards plug-in vehicles, and hybrid vehicles will be able to meet the entire New European Driving Cycle (NEDC) in the future. A primary development goal for the next generation of

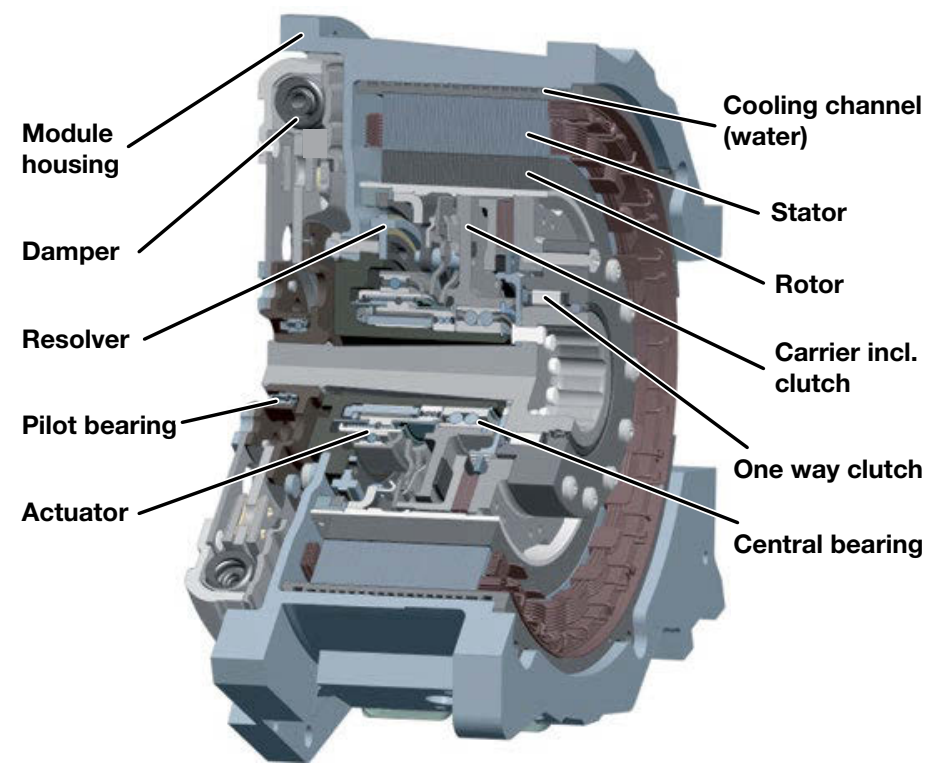

Figure 1 Cross-section of a second generation hybrid module 

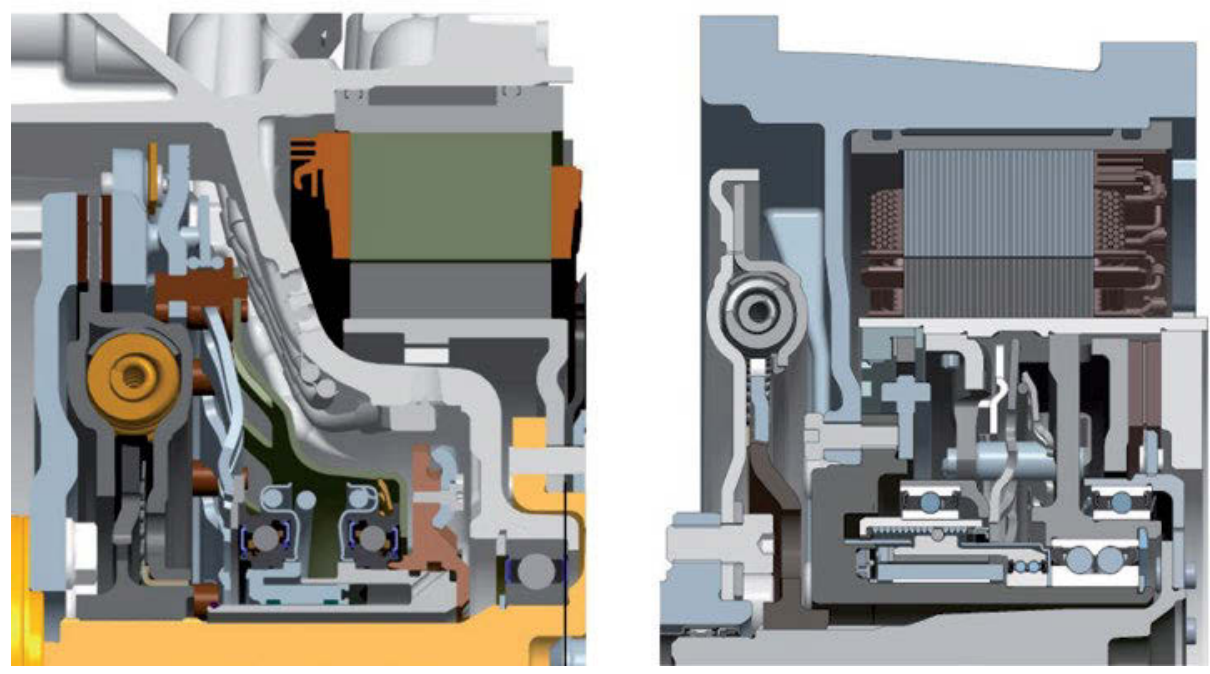

Figure 2 Installation dimensions of the hybrid modules: on the left, the first generation of 2010; on the right, the current stage of development

the Schaeffler hybrid module has therefore been to increase the power and torque density, while at the same time reducing the design envelope required. The installation location - between the internal combustion engine and the transmission - is also to remain unchanged. Moreover, as with the first generation, no modifications should be necessary to the hardware of the internal combustion engine or the transmission other than perhaps the addition of an electric pump for the transmission oil.

The second generation of the Schaeffler hybrid module (Figure 1) falls in line with this market trend and allows very high torques of up to $800 \mathrm{Nm}$ to be transferred. Transferring such high torques is made possible by a patented bifurcation of the power flow [2]. The torque of the internal combustion engine is channeled towards the transmission both via the closed disconnect clutch as well as via a parallel one-way clutch.

In each instance, the torque passes to an intermediate shaft via a vibration damper. This shaft has a double bearing support: a ball bearing in the area of the clutch and, at the front end, a pilot bearing that can be integrated into either the crankshaft or the damper. The output comes from the reaction plate of the disconnect clutch, which could be incorporated completely into the rotor.

The actuation and sensor elements that are functionally necessary have been fully integrated into the module. An electromechanical central release bearing optimized for this module takes care of actuating the clutch. A permanent magnet motor with an external rotor design is used to drive the actuator. 22 magnets have been glued inside the bore of the rotor, while the raceway for the ball screw is mounted on the outside.

The module has been designed in such a way that the disconnect clutch both starts the combustion engine and transfers the subsequent traction torque for powertrains with low torque requirements of up to $300 \mathrm{Nm}$. In order to achieve this torque, not only is the actuator's ability to engage the clutch utilized but also its ability to pull the diaphragm springs once the clutch has closed (push-pull principle). In order to use combustion engines with torques of over $300 \mathrm{Nm}$, a 
one-way clutch has been added to transfer the traction torque. This clutch is connected in parallel with the disconnect clutch, thereby offering two advantages: For one thing, this arrangement allows high clutch dynamics to be maintained along with very good control quality; for another, the time-consuming adjustment procedure after the combustion engine starts is no longer necessary since its speed is automatically matched by the one-way clutch when speeding up and coupling to the electric motor.

Thanks to the layout chosen, it was possible to downsize the installation dimensions considerably (Figure 2). The module's outside diameter has been reduced by $12 \mathrm{~mm}$ to $303 \mathrm{~mm}$, while the overall length has been shortened from $152 \mathrm{~mm}$ to $135 \mathrm{~mm}$ depending on the performance of the electric motor.

The integral components of the hybrid module used should be standardized regardless of the application in order to keep system costs as low as possible. Among other things, this applies to:

- the actuating elements

- the central bearing support

- the rotor support

- the clutch

- the rotor position encoder (resolver).

The modular layout remains unchanged irrespective of whether a conventional stepped automatic transmission, a double clutch transmission (wet/dry), or a continuously variable transmission (CVT) is involved. Even manual transmissions can be hybridized with the layout chosen. The housing and rotating components on the engine and the transmission are the interfaces that are specific to the customer or application. In other words, depending on the application, the vibration damper is adapted to the characteristics of the combustion engine used, and the drive plate to the transmission input.

In order to achieve maximum system efficiency, the Schaeffler hybrid module has been developed as a dry system. Relevant to the cycle, the input power of the actuator is under $10 \mathrm{~W}$. The bearing concept was optimized to such an extent that the drag torque is $<0.5 \mathrm{Nm}$ during electric-powered driving. The most important subsystem in this optimization process is the electric motor, the efficiency of which was able to be optimized to peak levels greater than $95 \%$. Any lost heat is conveyed by special thermally-conductive potting and a cold water jacket. Concerning the losses of the individual components, a thermal model provides confirmation of the maximum temperatures realized during operation. 
If the continuous output required by the vehicle is very close to the required peak output of the electric drive, it is also possible to design the module with a "wet" layout. In doing so, better heat dissipation is provided by oil volume flow around the rotor and the coil ends. Since dividing up the electric motor and the disconnect clutch into wet and dry regions would increase design complexity, having a wet clutch as well would be advantageous. The benefits of higher-performance cooling are offset by the efficiency disadvantage due to the added energy required for supplying the cooling oil as well the increase in drag losses in the gap between the rotor and the stator. Figure 3 shows the complete module in the wet installation space with an optional allowance (dotted line) for a damper on the output side. The clutch can be optionally actuated via a hydrostatic actuator [3] or through the transmission.

\section{Clutch system}

Since the traction torque of the combustion engine is transferred via the one-way clutch, the basis for the clutch design mainly depends on the torque that is required for combustion engine re-start. In doing so, it is necessary to use a high degree of precision to set a torque of approx. $110 \mathrm{Nm}$ (depending on the combustion engine) in the $<100 \mathrm{~ms}$ that is required to accelerate the crankshaft. Motor speeds during electric-powered driving of up to $4,000 \mathrm{rpm}$ result in a load cycle during which the crankshaft is accelerated to the corresponding differential speed. The wear reserve required by the linings is based on this cycle and a total number of 800,000 startups over the operating life of a plug-in hybrid.

As was already described above, the clutch is actuated by an electromechanical central release bearing (ECRB). The neces-

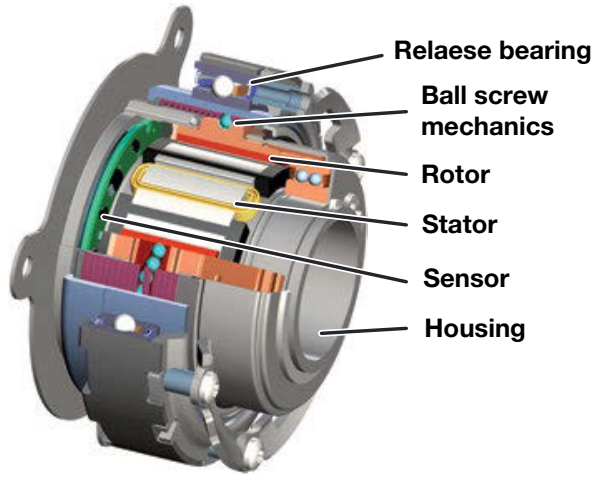

Figure 4 Interface of the electromechanical central release bearing (ECRB) in installation position

sary axial motion is generated via a ball screw drive directly linked to the rotor motion by means of a carriage running along a corresponding track (Figure 4). The actual release bearing that actuates the diaphragm spring is mounted on the carriage. The stroke from the touch point to the $100 \mathrm{Nm}$ point of the clutch can be traveled in less than $100 \mathrm{~ms}$, and the release force of the actuator is at most $1,800 \mathrm{~N}$ in the chosen design. Unlike with a hydraulic design, the electromechanical actuator can transfer forces in two directions. The fact that the clutch has been designed as a so-called "push-pull clutch" makes it possible to increase the transferable torque considerably. When not actuated, the clutch is closed.

\section{Electric motor}

The Schaeffler hybrid module uses a permanently excited synchronous motor that possesses high reluctance, thereby reducing the quantity of rare earth elements required. Since the clutch sitting inside the rotor is standardized, the electric motor always has the same inside diameter; thanks to the modular design, the outside diameter is adjusted depending on the required ca- 


\begin{tabular}{|c|c|c|c|}
\hline & & 41 kW Motor & 80 kW Motor \\
\hline \multicolumn{2}{|l|}{ Type } & PSM & PSM \\
\hline Torque & $\begin{array}{l}\text { peak (10 s) } \\
\text { des. }\end{array}$ & $\begin{array}{l}180 \mathrm{Nm} \\
100 \mathrm{Nm}\end{array}$ & $\begin{array}{l}280 \mathrm{Nm} \\
160 \mathrm{Nm}\end{array}$ \\
\hline Speed & $\begin{array}{l}\text { operation } \\
\text { burst }\end{array}$ & $\begin{array}{c}7,000 \mathrm{rpm} \\
>10,200 \mathrm{rpm}\end{array}$ & $\begin{array}{c}7,000 \mathrm{rpm} \\
>10,200 \mathrm{rpm}\end{array}$ \\
\hline Power & $\begin{array}{l}\text { peak (10 s.) } \\
\text { des. }\end{array}$ & $\begin{array}{l}41 \mathrm{~kW} \\
25 \mathrm{~kW}\end{array}$ & $\begin{array}{l}80 \mathrm{~kW} \\
48 \mathrm{~kW}\end{array}$ \\
\hline \multicolumn{2}{|c|}{ Efficiency $1,500-2,500$ rpm } & $>95 \%$ & $>95 \%$ \\
\hline \multicolumn{2}{|c|}{ Dimensions } & $\begin{array}{c}\text { D } 270 \mathrm{~mm}, \text { d } 182 \mathrm{~mm} \\
\text { L } 86 \mathrm{~mm}\end{array}$ & $\begin{array}{c}\text { D } 270 \mathrm{~mm}, \mathrm{~d} 182 \mathrm{~mm} \\
\text { L } 115 \mathrm{~mm}\end{array}$ \\
\hline \multicolumn{2}{|c|}{ Design voltage } & $264 V$ & $264 V$ \\
\hline
\end{tabular}

Figure 5 Technical data of the EM-H-270

pacity as well as on the available radial space. The available diameters are $260 \mathrm{~mm}$, $270 \mathrm{~mm}$, and $290 \mathrm{~mm}$. Further adjustment of the length of the electric motor results in an almost infinitely variable matching of motor performance to the application requirements.

The following table shows the designs of two electric motors of this type for plug-in hybrid vehicles of the $B / C$ and $D$ segments; (Figure 5).

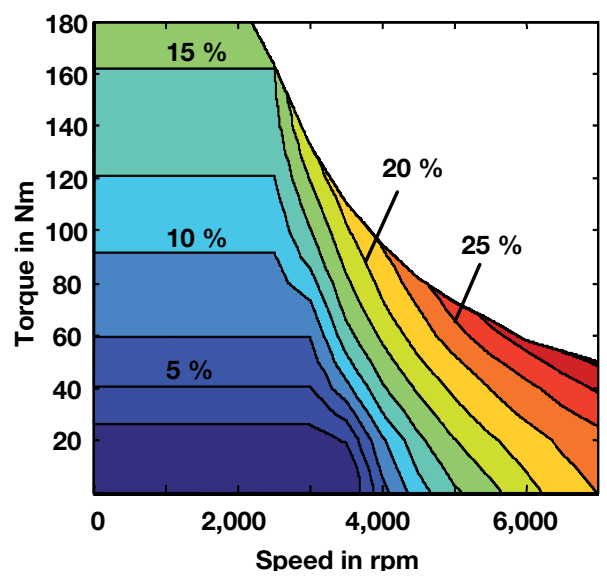

Figure 6 Reluctance percentage of electric motor EM-H-270-86
Following the electric motor design all the way to vehicle testing is part of developing the complete hybrid module at Schaeffler. As described above, the electric motor is designed with a high degree of reluctance. This initially results in the advantage that peak output can be provided up to high speeds. Furthermore, the efficiency of the upper speed range is clearly improved, and self-heating is reduced by cutting eddy-current losses in the magnets, thereby simplifying rotor cooling. The interdependence of torque and speed is represented in Figure 6.

\section{Power electronics}

Power electronics which, in future generations, will be slated as a hybrid module component, are still in the preliminary development stage (Figure 7). By using new electronic components, it is possible to achieve dimensions that are considerably more compact, thereby enabling them to be integrated in the module despite being positioned below the powertrain. This way the disadvantages involved with external wiring of power electronics and motors (costs, EMC, etc.) can be avoided. 


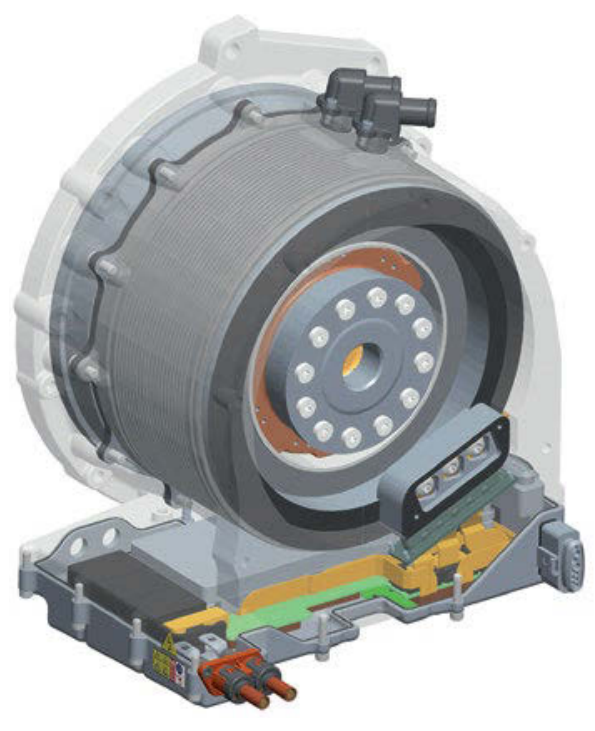

Figure 7 Hybrid module with directly mounted power electronics

The goal of production development is standardization on the functional level. The following advantages result when control and power elements are separated:

- The one control unit, once developed, can be reused again and again, since, as a rule, the basic functions remain nearly the same for all engine-power classes.

- The control and power units can thus be joined as flexibly as required by each existing installation space.

- The power output stages are freely scalable, and can be integrated into the system; at present, their designs range from $300 \mathrm{~W}$ to $100 \mathrm{~kW}$.

Besides reduced cabling expenditures, the linked cooling and one-piece housing design result in further cost and weight savings at the system level. Moreover, the overall installation space required is less than with discrete components.

\section{Active vibration damping}

Active damping of speed fluctuations in the powertrain by using an electric motor is an idea that was already pursued in the 1990s. Solutions aiming to provide the crankshaft with complete damping mainly failed due to the power demands involved. A basic requirement for effectively using this function is connecting a damper upstream of the electric motor. This powertrain layout is given by the module and enables designers to focus on the canceling function by targeting the main order of the combustion engine. Any additional energy requirements are thus limited to recording (sensor elements) and precise phase regulation in the range up to approx. $80 \mathrm{~Hz}$.

The basic function of such a system is portrayed schematically in Figure 8. In the process, the electric motor only smoothes out the already damped main order on the secondary side of the damper, which is possible with an extraordinarily low amount of energy. Thus, the torque required for cancelation (depending on the damper design) drops to about one tenth of the value required by the electric motor mounted directly on top of the crankshaft.

Active vibration cancelation is being developed with the goal of achieving ideal comfort and efficiency in an available installation space by means of mechanical damping, active vibration cancelation, and damping through starting element micro-slip. In the actual design process, an ideal compromise is struck between these two objectives that is primarily oriented to the required $\mathrm{NVH}$ vehicle behavior and the energy input required. 

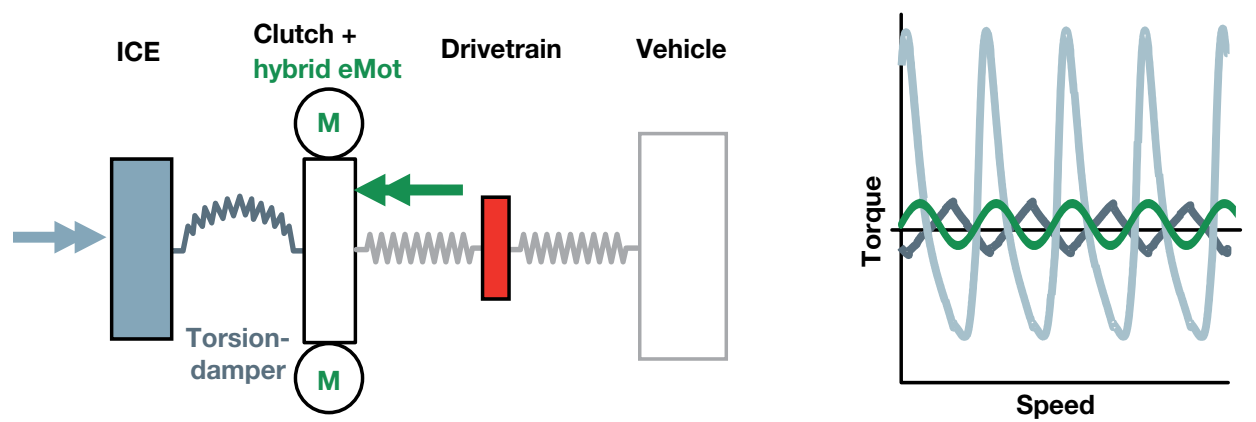

Figure 8 Functional diagram of active vibration damping in a hybrid powertrain

Particularly in the event that any powertrain resonances occur, the electric motor can be used to actively reduce them in a narrow speed range. In some cases, depending on the rigidity of the transmission, this approach will allow a second damper positioned downstream of the hybrid module to be eliminated.

By means of a simulation, it was possible to show that interplay between active damping via the electric motor and starting clutch micro-slip offers ideal energy conditions coupled with a high degree of vibration comfort (Figure 9). While the slippage generated in the clutch at $1,200 \mathrm{rpm}$ results in power losses of $700 \mathrm{~W}$, the electric motor operates at $350 \mathrm{~W}$ in this range. For speeds greater than $1,500 \mathrm{rpm}$, however, slippage regulation is more energy-efficient, while the power requirements placed on the electric motor continue to climb. Nevertheless, this ideal depends on the specific application and can therefore vary. What must be kept in mind is that these power losses refer to full-throttle operation of the internal combustion engine. In relevant cycles, these power requirements are much smaller.

For a long time, active vibration cancelation and the associated rapid changes in discharge current required for this strategy appeared to have a negative effect on the operating life of the battery.
Since, however, the overall battery size became significantly smaller with the introduction of plug-in hybrid vehicles, the energy throughput for cancelation is reduced accordingly, down to less than $2 \%$. What is more, it has since been empirically proven that cell damage due to cyclic micro-discharge events is much less than originally feared. This is especially true when there is no ion conversion in the battery, i.e. if the current is regulated within the generator or drive mode. [4]

The development of special control algorithms for active vibration cancelation is currently being tested on internal combustion engine test rigs and in vehicle tests.

\section{The 48-volt hybrid module}

\section{Motivation}

The first steps with hybridization can naturally be taken using lower power systems. For one thing, this approach makes it possible for the voltage to stay below the safety-critical value of $60 \mathrm{~V}$. What is more, the expenditure for the complete system can be decreased considerably. In particular, the 


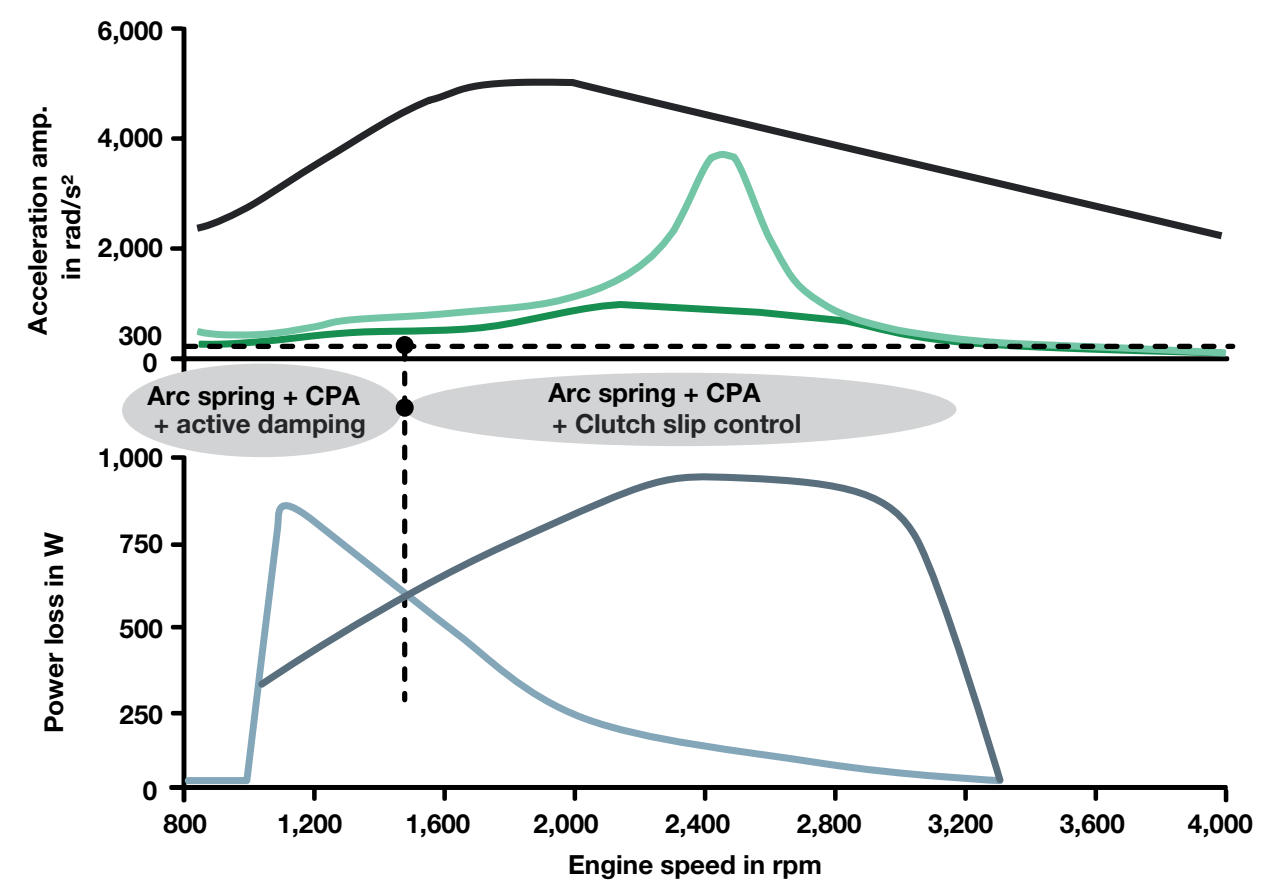

- Engine

- Clutch slip control

- Transmission input shaft with Arc spring damper

- Transmission input shaft with Arc spring damper + CPA

-- target

- active damping

Figure 9 Power losses from combined active vibration damping of an electric motor and slippage monitoring, depending on the engine speed

energy storage device is reduced in size by a factor of three, with a useful capacity of approx. $300 \mathrm{Wh}$. If the new voltage level is used, equipping vehicles with a mildly hybridized drive is all that is necessary to make substantial consumption savings possible. Simulations show, for instance, that a $12 \mathrm{~kW}$ electric motor with an asynchronous design can lower the consumption in the standard European driving cycle by around $10 \%$.

When a hybrid module with an integrated transmission is used, this system is more efficient due to the fact that the gear ratio can also be used to operate the electric motor with ideal efficiency.
Compared to HV systems, ideal efficiency comes at lower speeds since the combustion engine runs more of the time, thereby determining the speed of the electric motor.

A further and significant improvement in fuel consumption can be achieved by replacing today's conventional asynchronous motor with a synchronous motor with a higher power density. The layout and the effect on consumption are explained in greater detail in the chapter on the 48 -volt electric motor. 


\section{Combination with a manual transmission}

As a rule, the structural design of a hybrid module employs the same concepts when used with a 48-volt application as with a high voltage application. One particular challenge stems from the fact that manual transmissions are still frequently used today in price-sensitive compact and mid-sized segments.

Using function matrices, Schaeffler has chosen four designs from a host of possible topologies, studying the specific advantages and disadvantages that distinguish them when it comes to linking the combustion engine to the fixed-transmission hybrid module:

- Impulse clutch

- Adaptation of the existing hybrid module for $48 \mathrm{~V}$ without further changes

- One-way clutch combined with a lockup clutch - coaxial

- One-way clutch combined with a lockup clutch - axially parallel

Due to this module's limited capacity, it is not feasible to start the engine via the disconnect clutch. A basic distinction was therefore made initially between continuing to start the combustion engine via the conventional starter or by means of the rotating masses. This inertia is utilized by using an impulse clutch (Figure 10), and the combustion engine is brought up to speed solely by closing the clutch. Involved here is a very rapidly actuating clutch that has to be able to transfer very high fluctuating torques of up to $1,500 \mathrm{Nm}$. This clutch is not modulated, but rather is either completely opened or closed. An important requirement for this system is reducing the crankshaft related inertia to a minimum. The complete hybrid module is installed along with the electric motor on the side of the crankshaft and is supported by

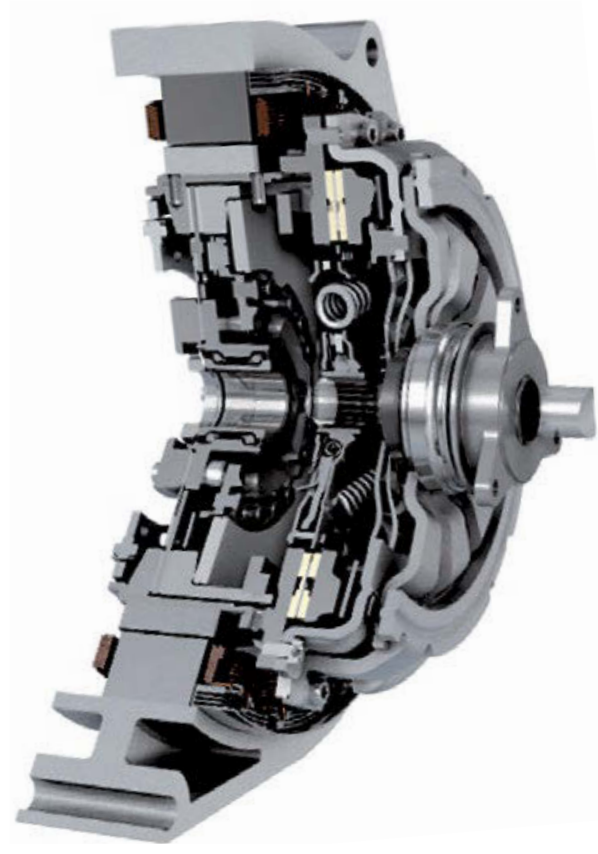

Figure 10 Structural design of an impulse clutch

two rows of ball bearings. The clutches are actuated by two release bearings which are controlled via a diaphragm spring (startup clutch) and a lever spring (disconnect clutch). The expenditure involved in the design is similar to that of a double clutch in a double clutch transmission.

Other combustion engine concepts involve a separate starter system in order to re-couple the engine after a coast/drive phase. In this way, the use of a one-way clutch as a low-cost alternative to the standard clutch is conceivable. With this topology, the combustion engine is started by the conventional starter and mechanically coupled once it reaches the speed of the electric motor.

The disadvantage of such a solution is that a vehicle parked in first gear would no longer have a "gear brake." Since the one- 
way clutch does not block the powertrain in one direction of rotation, the vehicle would start to roll if the parking brake is not set on a hill.

This disadvantage can be avoided by equipping the one way clutch with a locking function. To this end, for instance, a shift sleeve can be used that provides a form-fit connection between the secondary damper side and the rotor holder. This spline connection is initially closed and can be opened via a tie-rod linked to the starting clutch. A hydrostatic clutch actuator (HCA) - produced by Schaeffler recently for double clutch transmissions - is used as for actuation [5]. Moreover, particularly with a small energy storage device and a high state-of-charge (SOC), it is necessary to be able to re-couple the combustion engine in order for it to take up the driving torque. This function is facilitated by one-way clutch locking as well. Since actuation of the already existing starting clutch can also be used for the shift sleeve, no additional actuator is necessary.

Locking the one-way clutch also ensures that the driving feel does not change for the driver during the drive phase when the energy storage device has a high SOC. The combustion engine then takes up the driving torque again.

With respect to time and comfort, a warm start from a stop-start situation can be initiated directly via the 48 -volt electric motor.

The configuration in the installation space can be either axially parallel or coaxial. An axially parallel layout permits the use of an asynchronous motor which already exists due to the development of the belt-driven starter generator. In this system, torque is transferred via a belt with two-fold to three-fold ratio.

An essential requirement for realizing such a layout is that the installation space above the clutch bell must be able to be used for the electric motor (Figure 11). This appears to be feasible, especially with front-transverse powertrains. This layout results in the least amount of powertrain lengthening.

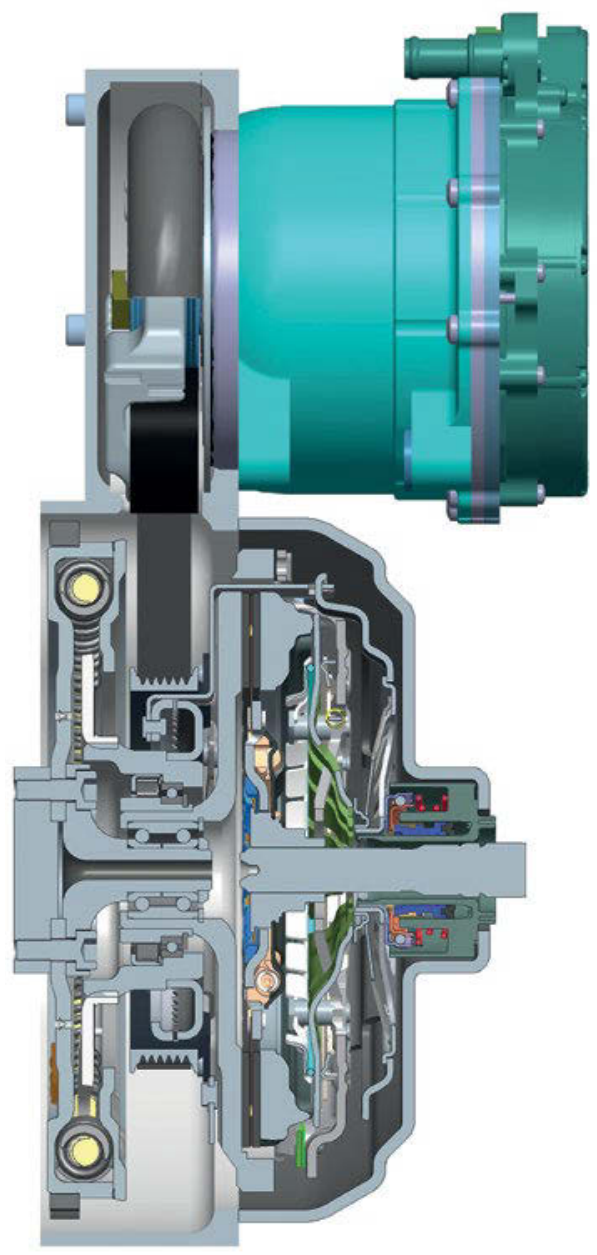

Figure 11 Typology and structural design of the hybrid module with an asynchronous motor in parallel arrangement 


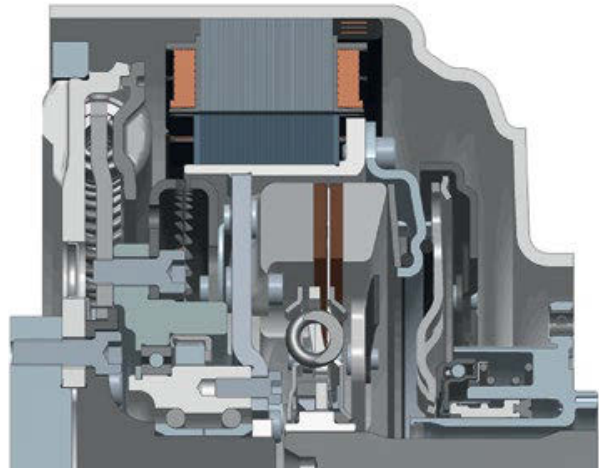

Figure 12 Topology and structural design of the hybrid module with a locking one-way clutch in coaxial arrangement

In comparison, the coaxial model is shown in Figure 12. The one-way clutch, one-way clutch locking mechanism, and, in part, the starting clutch are radially nested under the rotor. Thanks to good thermal coupling of the electric motor, the stator can be aircooled.

\section{8-volt PSM electric motor}

For cost reasons, asynchronous motors are primarily being introduced to the market for mild hybrid applications; a fact that is also

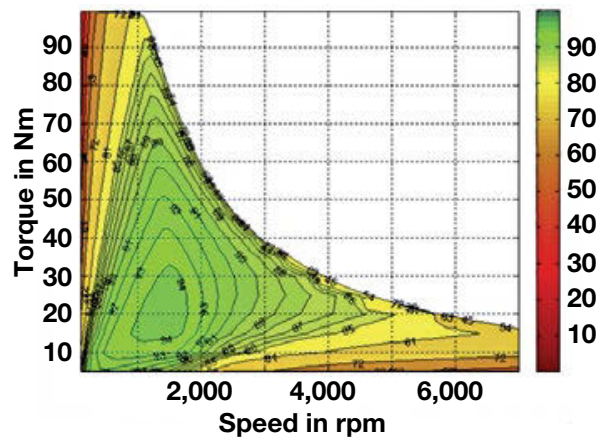

Figure 13 Efficiency range of a permanentlyexcited synchronous motor employed in the 48-volt hybrid module recommended in Figure 11. In order to take advantage of the available installation space, especially with the coaxial layout shown in Figure 12, it is preferable to use a permanently-excited synchronous motor (PSM), the power density of which is up to $30 \%$ greater depending on the demand. In addition, the greater efficiency of the PSM in conjunction with optimizing the speed range relevant to the cycle (Figure 13), yet again results in a markedly improved $\mathrm{CO}_{2}$ balance.

The increased efficiency of the PSM compared to the ASM results in an added consumption benefit of up to $3.5 \%$. This delta is due to improved efficiency - and also to the fact that any recuperated energy that cannot be directly reused in the onboard electric system "flows through" the electric motor multiple times.

\section{Operation strategy with a manual transmission}

Driver acceptability is vital for successfully launching mild hybrid vehicles with manual transmissions in the market. An essential component for this is that the powertrain always delivers the acceleration required by the driver. The power distribution between the combustion engine and the electric motor must be configured in such a way that it is practically imperceptible to the driver.

The combustion engine not only switches on automatically when a lot of power is required, but also for high electric motor rpm levels when the driver does not upshift. For acoustics reasons as well, the switch-on point is at about 3,500 rpm. In order to maintain good vehicle drivability, the constant speed of the electric motor in the consumption cycle is limited to $50 \mathrm{~km} / \mathrm{h}$ despite reduced $\mathrm{CO}_{2}$-emission potential. At higher speeds, the combustion engine is only decoupled during the drive phase. 
As has already been recommended for pure start-stop systems, due to the sailing function and improved market acceptance, the starting clutch has been automated for this hybrid module. This configuration makes it possible to use creep in the starting clutch in order to be able to realize a very comfortable motor startup feel.

\section{Outlook}

At present, B-model testing is being conducted on the next generation of highvoltage models of the Schaeffler hybrid module. The current projects cover all conventional automatic transmissions. In the process, it has become clear that the hardware for the various configurations can indeed be designed with standardized basic components.

With a P2 hybrid module, it is already possible to realize consumption benefits of around $10 \%$ based on a 48-volt system with an asynchronous motor. Additional potential of up to $3.5 \%$ is available by using a synchronous motor. Combined with the possibility of moving the vehicle at low speeds of up to approx. $15 \mathrm{~km} / \mathrm{h}$ using only electricity, this module makes for entry-level electrification that is ideal.

Thanks to mild hybridization, manual transmissions are fit for the next generation. Vehicle testing will show whether drivers accept the extra functions without noticing any sacrifices in comfort. Adjusted acoustic factors and automated clutch action will help with this.

\section{Literature}

[1] Wagner, U.; Reitz, D.: The future comes automatic: Efficient automatic transmissions provide a basis for hybrid capable drive trains. $9^{\text {th }}$ Schaeffler Symposium, 2010

[2] Schutzrecht DE 102012207941A1: Hybridmodul für einen Triebstrang eines Fahrzeuges.

[3] Mueller, B.: Transmission Actuation: Downsizing Complexity, Upsizing Performance. $10^{\text {th }}$ Schaeffler Symposium, 2014

[4] Wang, J.: Cycle-life model for graphite-LiFePO4 cells. Journal of Power Sources, 2011

[5] Mueller, B.; et. al.: Smaller, Smoother, Smarter: Advance development components for double-clutch transmissions. $9^{\text {th }}$ Schaeffler Symposium, 2010

Open Access. This chapter is distributed under the terms of the Creative Commons Attribution Noncommercial License, which permits any noncommercial use, distribution, and reproduction in any medium, provided the original author(s) and source are credited. 